\title{
Stimulated Brillouin scattering in highly birefringent multimode tapered chalcogenide photonic crystal fiber for distributed optical sensors (Retraction Notice)
}

\section{Amira Baili, Rim Cherif, Mourad Zghal}

Amira Baili, Rim Cherif, Mourad Zghal, "Stimulated Brillouin scattering in highly birefringent multimode tapered chalcogenide photonic crystal fiber for distributed optical sensors (Retraction Notice)," Proc. SPIE 9927, Nanoengineering: Fabrication, Properties, Optics, and Devices XIII, 992717 (15 September 2016); doi: 10.1117/12.2238068

Event: SPIE Nanoscience + Engineering, 2016, San Diego, California, United States 


\title{
Stimulated Brillouin scattering in highly birefringent multimode tapered chalcogenide photonic crystal fiber for distributed optical sensors (Retraction Notice)
}

\author{
Amira Baili, Rim Cherif, Mourad Zghal \\ SUP'COM (Tunisia)
}

Proc. SPIE 9927, Nanoengineering: Fabrication, Properties, Optics, and Devices

XIII, 992717 (September 15, 2016); doi: 10.1117/12.2238068

\author{
From Conference Volume 9927 \\ Nanoengineering: Fabrication, Properties, Optics, and Devices XIII \\ Eva M. Campo; Elizabeth A. Dobisz; Louay A. Eldada \\ San Diego, California, United States | August 28, 2016
}

This paper, originally published on September 15, 2016, was retracted from the SPIE Digital Library on October 6, 2016, due to a high degree of similarity between portions of the text of the paper to the following publications:

J. Tchahame, J. Beugnot, A. Kudlinski, and T. Sylvestre, "Multimode Brillouin spectrum in a long tapered birefringent photonic crystal fiber," Opt. Lett. 40, 4281-4284 (2015). doi: 10.1364/OL.40.004281.

W. W. Ke, X. J. Wang and X. Tang, "Stimulated Brillouin Scattering Model in Multi-Mode Fiber Lasers," in IEEE Journal of Selected Topics in Quantum Electronics, vol. 20, no. 5, pp. 305-314, Sept.-Oct. 2014. doi: 10.1109/JSTQE.2014.2303256. 